\title{
Stakeholders' Perceptions of Coastal Tourism and Its Management: a Case of Nonoti Beach Rural Community in Kwazulu-Natal, South Africa
}

\author{
Dr Mabuyi Gumede
}

\begin{abstract}
This paper focuses on various stakeholders' perception on coastal tourism development at Nonoti Beach community. This area is located in the land that was obtained through land claims where local communities were promised low cost housing and beach resort development. However, these promises have not been fulfilled. This paper thus highlights the daily struggles of rural communities whose lives have not been improved despite develop promises to promote coastal tourism. Based on mixed research methods and stakeholder theories, this paper argues that despite the good intentions of the stakeholders' development promises, the plan that is part of the land claims settlement has not materialised, which is to the detriment of the community. This paper thus recommends that the stakeholders mandated to develop coastal tourism in these communities manage conflicting interests and engage in an integrated development plan for the newly acquired land to efficiently benefit and sustain the communities.
\end{abstract}

Keywords - Land Restoration, Stakeholder Perceptions, Sustainable Livelihoods.

\section{INTRODUCTION}

The rural communities in South Africa and in other parts of the world live under extreme poverty and the majority are without any social security (Gumede 2018). South Africa in its 24 years of democracy, but the remote rural areas of this country are still living in the shadow of the apartheid legacy, which has resulted in the under development of these areas. Rural areas live under extreme poverty which is perpetuated by the lack of basic infrastructure, high illiteracy levels resulting in high unemployment rates (Aliber 2013). The Nonoti Beach community is one of the rural communities in KwaZulu-Natal which comprises of approximately 300 households with about 1600 beneficiaries of state grants (Sivest 2011). Most rural areas in South Africa are faced with various socio-economic problems such as high illiteracy rates, unemployment, the scourge of HIV/AIDS pandemic and poverty (Walker 2013, Lahiff 2010). The study area is not immune from these challenges therefore, when they received a settlement on the decade long land claim process, they decided to invest in

Dr Mabuyi Gumede, University of KwaZulu-Natal, School of Social Sciences, Howard College, Durban, South Africa. development. As part of the settlement, the claimants were promised low cost houses and the development of a beach resort that was aimed at sustaining their livelihoods through training, infrastructure development, job creation and profit sharing. Fourteen years after this settlement was reached, but none of these plans have come to fruition. The proposed resort has not materialised and neither the low cost houses have been built. This paper aims to highlight the daily struggles of previously dispossessed communities when the land is restored back to them and the narratives of various stakeholders mandated to develop and promote tourism for the benefit of the communities. What is of note is that the narratives of those in the decision making positions are often times contradictory to those of populations at grass root level.

\section{THEORETICAL FRAMEWORK}

This study is framed on the stakeholder theory which proposes that various stakeholders should be given simultaneous attention in order to create a balance between their conflicting interests and how they can work collaboratively to develop an integrated management plan to deliver environmental, social and economic benefits (Harrison et al. 2013). Various stakeholders participated in this study, due to their invested interest in coastal tourism in the study area. Some of the stakeholders are government agencies that have a mandate to promote and enhance tourism development, others have a responsibility to develop policies aimed at achieving this mandate. Others play an important role of monitoring the implementation of those policies. The local community as a significant stakeholder in coastal tourism taking place in the area is expected to play a pivotal role by participating actively in coastal tourism issues in order to maximize benefits accruing to them. The Stakeholder Theory proposes that stakeholders should be treated well and their interests be managed in a way that assists in creating value along a number of dimensions. Harrison et al. (2013) propose that "stakeholder interests are inseparably connected in a system of value creation in which each stakeholder provides resources or influence in exchange for some combination of tangible and/ or intangible goods"..

\section{RESEARCH METHODOLOGY}

This study was conducted using the mixed methodology 
approach since it provides a broader perspective on the phenomenon being studied and avoids bias through triangulation. The stakeholders that participated in this study have been grouped into four categories comprising of, the members of the local community, political bodies, the government agencies and tourism businesses operating in the study area. The first category was a sample from the local community which was represented by Inqaba Trust, an organisation that was chosen by the community to be their ears and eyes in the discussions leading to the development of the proposed beach resort. The second category was selected from the political bodies which comprised of the democratically elected councillor as well as two representatives from the iLembe District Municipality. The other category of the stakeholders who participated in this study is that of the government agencies that have a mandate of spearheading tourism development and promotion in the study area and these were composed of Tourism KwaZulu-Natal (TKZN) and Enterprise iLembe, a development agency aligned to the iLembe District Municipality. The last category was sampled from the tourism businesses operating in the nearby towns of KwaDukuza and Zinkwazi since there is no formal tourism at Nonoti Beach as yet. All these stakeholders have equal responsibility in developing an integrated plan to create balance in the decisions that they make, despite their rather conflicting interests.

\section{FINDINGS}

In post-colonial South Africa, the government plays a significant role in the development, promotion and management of tourism, considering the fact that the development of this industry became aggressive only after 1994 in this country. Tourism as an economic sector is perceived as the lost opportunity in South Africa due to the apartheid era, which lasted for decades (Meskell 2011, NTSS 2012). Even now, in the post-apartheid era, most black communities still do not have a clear understanding of tourism and the potential this economic sector has of improving their lives. This is in contradiction with Priority 8 of DEA (2014) whose focus is on strengthening awareness, education and training to build capacity, which proves that there are brilliant policies in the country, whose implementation is not articulated into practice. The main goal is to ensure that the public and decision-makers are appropriately aware, educated and trained, where applicable, to be able to take collective responsibility for managing and protecting the coastal environment in the manner that is socially, economically and ecologically justifiable, and which should result in the sustainability of the marine environments and associated resources.

The national, provincial and local government has a collaborative role to play in the development of tourism. Whilst the national government is responsible for the formulation, monitoring and updating of national tourism policies in collaboration with other relevant stakeholders, the provincial government is responsible for formulating policies, which are applicable to their area, in accordance with the national policy (NTSS 2012). This tier of government is also responsible for monitoring the implementation of those policies. The local government is then responsible for the provision and maintenance of tourism facilities. It is the responsibility of the local government to market, coordinate and administer tourism initiatives in the locality. It is also their responsibility to facilitate and coordinate the participation of local communities in the tourism industry (NTSS 2011). The government agencies that participated in this study are Enterprise iLembe and Tourism KwaZulu-Natal which is discussed below.

\section{A. Tourism KwaZulu-Natal (TKZN)}

TKZN is a provincial government agency that is mandated with the responsibility of marketing the province of KwaZulu-Natal, enhancing international, national and domestic tourism. This agency is also responsible for conducting research on tourism trends and facilitating development. TKZN is mandated present new products to appeal to tourists and assist local communities to participate in tourism. Respondent 5 confirms this as he mentions:

Regarding coastal tourism development, TKZN has identified a gap in this niche area, more especially in coastal/ beach resort development. It is also the responsibility of this agency to encourage local communities to be part of coastal tourism, ensure active involvement and participation as well as monitoring this process on a continuous basis to ensure that the local community reaps maximum results from coastal tourism projects and initiatives.

Regarding the extent to which the local community participates in the management of tourism at Nonoti Beach, the greatest challenge is that the level of participation is minimal, more especially amongst the community members at grassroots level. Respondent 5 (TKZN Representative) confirms this when he states:

This project of developing a beach resort at Nonoti Beach is not off the ground yet, it is still being put together and the delays result mainly from the challenges with the MEC. The land that was restored back to the community of Nonoti Beach is planned for two main projects, namely, the low cost housing project as well as the development of the beach resort that is aimed at sustaining the lives of the local community through the creation of jobs. The local community wants houses and the delays in the implementation of the housing project makes them to lose hope in the entire project plan, which limits their participation in the issues of tourism development and management in their neighbourhood.

As reflected by Respondent 5 above, Ndlovu et al. (2017) acknowledge the importance of the National Tourism Sector Strategy (NTSS 2012). This strategy has been developed to identify and promote local destination areas with a tourism product potential and to ensure that local communities benefit from tourism. In the study area, there are plans of leasing the land to investors and the community to have a stake through the profit sharing of the dividends. This is confirmed by Respondent 5 who suggests that:

...the development of Nonoti Beach Resort stands to benefit the community by providing them with education and training, awareness programmes on the ecosystems, profit sharing as well as the creation of jobs. Once this anticipated project takes off, there will be training on the rules governing trustees as well 
as on their roles based on agreements on shareholding. There will also be training of relevant committees on finances, tour guiding, entrepreneurship, etc.

Based on the observation above, various scholars (Ndlovu et al. 2017, DEA 2012, Meskell 2011, and Hottola 2009) have identified the historical exclusion of the black communities, low levels of education, lack of tourism related skills and commercial business knowledge as a major challenge limiting the participation of local communities in coastal tourism that is occurs in their localities. Respondent 7 indicated that the planned training will be monitored and evaluated by various stakeholders with a stake in coastal tourism, stakeholders such as TKZN, TIKZN, IDC, THETA and TEP to ensure that it meets the needs of the previously disadvantaged and marginalized community of Nonoti Beach. In addition, the significant role that should be played by institutions of higher education in enhancing the local community participation in coastal tourism was proposed by Respondent 5 who mentioned that:

...the institutions of higher learning need to play an active role in encouraging the local community participation in coastal tourism taking place in this area. Their responsibility would be to conduct a skills audit as well as researches on the productivity of the land and suggest other economic activities that could be possible in the study area if agriculture was no longer possible due to the aridity of the soil.

Respondent 5 further indicated that the training planned for the new landowners will be on a continuous basis and the evaluation of this training should be conducted annually. In addition, Respondent 5 suggests progress reports on the training will be presented to investors, the committee representing the community and other relevant stakeholders, as it has been confirmed in Gumede (2009), that stakeholders' input is essential to suggest ways to improve the management of coastal tourism and to alleviate vulnerability. Gumede (2009) reiterates that it becomes imperative to involve all the relevant stakeholders in order to develop approaches to create synergy and alignment amongst their conflicting interests for mutual beneficiality.

The shared benefits are also validated by (Hillenbrand, Money and Ghobadian 2013) who emphasises the pivotal role of good working relations amongst various stakeholders in practicing responsible tourism, thereby achieving sustainability through the conservation and preservation of the marine resources. The findings of this study reveal that the relationship between TKZN and the community of Nonoti Beach as significant stakeholders in coastal tourism in the area is collaborative and typified by mutual respect which augurs well for sustaining good relationships. This is confirmed by Respondent 5 when he points out that

There is great and open lines of communication between ourselves as TKZN and the community of Nonoti Beach and this is because TKZN offers great assistance to the community and this organization is on the side of the community.

Despite Respondent 5 capturing this relationship as collaborative and mutual, it begs the contradiction of why there has been a delay of this project. Evidently, these differences of perceptions by this stakeholder exist on what is mutual respect and collaboration. Available literature (Leijzer and Denman 2013, Jury 2011) emphasizes the important role that is played by sharing best practices with those communities that have had similar experiences. During the interview, the representative from TKZN affirmed this when he indicated that it could be beneficial to the local community of Nonoti Beach to take committee members and community leaders to get first-hand experience on the best practices in other communities which had similar experiences, that is, whose land was restored and who have since lived sustainably on restored land.

\section{B. Enterprise iLembe}

Enterprise iLembe is an economic development agency of iLembe District Municipality spearheading the sectors of agriculture, tourism, manufacturing and services as economic sectors contributing to the economy of iLembe District Municipality, the province of KwaZulu-Natal and the country at large. This agency acknowledges coastal tourism as one of the key drivers in iLembe, therefore, it plays a role of facilitation, policy formulation and implementation as well as social facilitation. This agency is also responsible for marketing tourism in and around iLembe District, the region where Nonoti Beach is located.

Regarding the plans Enterprise iLembe has to improve the lives of the local community of Nonoti Beach, the following is the response of Respondent 6 confirming the close relationship between this government agency and other stakeholders:

This government agency works in collaboration with other partners such as TKZN, TIKZN, KwaDukuza Local Municipality, and others in ensuring that this coastal tourism project creates jobs, empowerment and skills development. The collaboration between Enterprise iLembe and the other stakeholders is significant since the stakeholders' direct participation is fundamental to protecting biodiversity as they may actively oppose or support conservation actions.

The notion by Respondent 6 above is confirmed by Cavlek, Ladkin and Willis (2017) where they propose that for any form of sustainable development and successful conservation efforts, it is necessary for all the stakeholders to be involved. Respondent 6 elaborates on this when she states that:

All the stakeholders that are mandated to develop a plan to develop and promote tourism in the study area, agree that through the development of Nonoti Beach Resort, the local community will benefit greatly through ownership, job creation, skills transfer and to ensure long-term sustainability of the community. Training and skills transfer forms part of the bigger project and various partners such as EDTEA have been lobbied in to design the training plan for the local community, to enable them to have skills to work in the tourism project that is planned for Nonoti Beach.

As much as Respondent 6 above indicated that a training and skills transfer form part of the bigger plan, but this is contradictory to what was shared by the members of the local community, whereby they revealed that they have not received any training and the skills they have do not qualify them to work in the tourism industry, since their training was on construction and plumbing to capacitate them to get jobs during the construction of the proposed resort for Nonoti Beach. 
DEA (2017) proposes that it is essential for the training that is meant to empower the local communities to go through the process of monitoring and evaluation to ensure that it is relevant and significant. This was confirmed by Respondent 6 when she affirmed that

The evaluation and monitoring of training will be the responsibility of all the partners involved, both government and the private sector and the monitoring and evaluation of this training will be done regularly, that is, biannually at the most. The progress reports will be presented to the project steering committee in place in collaboration with the project partners, for own assessment.

According to Jury (2011), natural resources are fundamental to food security, poverty alleviation and socio-economic development, but cautions that the level of resource exploitation sometimes becomes rife. As much as tourism development along the coast usually has benefits to the local community, however, since the development of Nonoti Beach Resort is still underway, so no jobs have been created presently, but the jobs potential is in various sectors, sectors such as hospitality, environment, construction, etc. Therefore, coastal tourism in the study area is not contributing much to the wellbeing of the local people. Respondent 6 indicated that, as much as relationship between the Enterprise iLembe and the members of the local community is great, but it can still be improved. Enterprise iLembe has a social facilitation unit that works closely with the community where the local community is also part of the PSC. The challenges highlighted by Enterprise iLembe that limit the local community's participation in coastal issues included, amongst others, challenges of land zoning as well as Environmental Impact Assessments that take too long to be processed, thereby delaying the implementation of the entire project. The observation above indicates the lack of integration in the work of different government departments and which was identified as the reason for the delay in the building of the proposed resort.

The sea could be regarded as a resource that the community could manage in what is termed CBNRM, however, Mbaiwa (2011) cautions that CBNRM has failed in countries such as Botswana, due to the lack of understanding of this process by the members of the local community. This researcher cites the lack of marketing, entrepreneurial and finance management skills amongst the community members as result failure of CBNRM projects. This failure could be a possibility in the study area as is indicated by Respondent 8, a representative from iLembe District Municipality when he stated that

The local community of Nonoti Beach currently does not have the required skills to take part in the management of coastal tourism at Nonoti Beach, therefore are not well positioned to maximize benefits accruing to them through tourism that is taking place in their locality.

Respondent 8 is positive about the participation of the local community in the management of tourism in the study area as he indicated that community members are part of the PSC through Inqaba Trust whose members have been selected by the community itself to represent them. He further proposed that skills such as business management, financial management, customer service, marketing skills, ICT, construction and maintenance as well as hospitality management could be of benefit to the local community and would enable them to participate actively in the management of coastal tourism development that is planned for Nonoti Beach.

As much as coastal tourism is taking place at Nonoti Beach, but it is currently benefitting no one, since it is informal in nature. The ultimate aim is for the community to be the main beneficiaries once the proposed beach resort is constructed and is operational. The planned resort is anticipated to be a spin off for jobs and skills transfer through collaborating with the private sector, therefore, contributing to the economic growth for the district as a whole and the local community. When the planned resort is up and running, the distribution of income benefits from tourism partnership agreements will be determined by the trust that has been formed and this should form part of the trust charter.

According to Respondent 6, decisions regarding the development and management of tourism at Nonoti Beach are made by PSC through a consultative process with all the stakeholders with a mandate to develop and promote coastal tourism in the study area. The decision-makers at Nonoti Beach are Inqaba Trust and the community elects the members of this trust to represent them and their needs. The expectation of the local community about coastal tourism at Nonoti Beach is that they would like to see the proposed project developed and the houses built for them. They also expect job creation and direct income benefits.

\section{Political bodies with a stake in coastal tourism in the study area}

Amongst the political bodies that participated in this study is the KwaDukuza Local Municipality that was represented by the democratically elected leadership in the form of the ward councillor of Nonoti Beach. Nonoti Beach is located in Ward 3 of the KwaDukuza Local Municipality. The councillor is a democratically elected local representative who has a unique and privileged position with a potential to make a real difference to people's lives. This individual engages with residents on a wide range and takes on an important community leadership role. The councillor is expected to contribute to development of policies and strategies and is involved in scrutinizing council decisions. The councillor acts as a bridge between the community and the council. Regarding the stakeholder with a custodial role of spearheading coastal tourism and the level of participation of the local community in the study area, the councillor clearly indicated that this economic sector is not under any specific stakeholder's custodial role, but it is the responsibility of a number of stakeholders who work cooperatively with one another. According to the councillor, the local community is, to some extent, involved in coastal tourism at Nonoti Beach. This is confirmed by this respondent when he stated that

Coastal tourism in the area is not spearheaded solely by a specific stakeholder but by various stakeholders, stakeholders such as the iLembe District Municipality, KwaDukuza Local Municipality and the local community of Nonoti Beach, which is actively involved in coastal tourism development at Nonoti Beach. There is a co-operative that is composed of both men and women from the local community who engage in fishing 
and the removal of mussels from the sea. The local community takes the safety and security of visitors visiting this coastal destination as their own responsibility and this is evident in the fact that there are beach patrols from the community. Other community members are responsible for the removal of alien plants. It is in the Integrated Development Plan (IDP 2012-2016) of KwaDukuza Local Municipality to upgrade Nonoti Beach and it is in the plan of the local municipality to train lifeguards that will take care of the tourists visiting this coastal destination. The local community is prioritised for the proposed training.

The sea where the study area is located could be perceived as a natural resource that the local community could use to sustain lives through what is known as Community Based Natural Resource Management (CBNRM). Sowman and Wynberg (2014) cautions that CBNRM is complex but could be operational if the central government could be willing to devolve and protect the rights of the local people to manage, benefit from and sell the resources the sea has to offer as well as utilizing the local people's ability to manage these rights. The councillor perceives the local community of Nonoti Beach to be having some skills, which include amongst others, fishing, extraction of mussels as well as selling of these resources to sustain livelihoods. This respondent cautions that there is a lack of tourism related skills, such as management, hospitality, hotel and financial management skills in the local community to assist them with the marketing and pricing of their products. This lack of relevant skills limits their active participation and involvement in the management of this coastal destination. It was also indicated that there is no clarity regarding the available skills since no skills audit has ever been conducted in the past five years and suggested that skills audit be included in the Integrated Development Plan (IDP) of the local municipality.

The councillor identified lack of proper management of Nonoti Beach as the main challenge the local community faces in the management of coastal tourism in the study area. Since the upgrading of the area is still underway, therefore, this tourism destination lacks the basic infrastructure such as running water, electricity supply and proper sanitation. The other problem is the lack of tarred road leading to Nonoti Beach. This participant suggested awareness programmes to educate the local community on the significant role that is played by tourism and the importance of positive behavior that would encourage tourists to visit Nonoti Beach. According to the councillor, these programmes could encourage the local community to avoid vandalizing the available natural resources but instead enhance the practice of responsible tourism. According to Meskell (2011), supporting local people and respecting local cultures in tourism are perceived as highly beneficial for the empowerment of the local community, thereby resulting in poverty reduction (Hottola 2009). This is confirmed by Respondent 4 where he states that

As members of the local community, we treat our visitors well since we know that we have something tangible to benefit from the process of tourism that is taking place in the neighbourhood. We also believe that if development in our ancestral land respects us and our cultures, this could encourage us to practice responsible tourism and take responsibility and ownership of the marine resources in the area, which, we believe will in turn encourage more tourists to visit our place. We also believe that it would be beneficial to us as members of the local community to carve partnerships between the well-established tourism businesses and the emerging SMMEs from amongst the local community to enhance tourism growth leading to economic empowerment of the local community.

The councillor shared the sentiments of Enterprise iLembe regarding the main beneficiaries of coastal tourism at Nonoti Beach where it was indicated that, as much as tourists visit this destination, but no particular person, organization or the local community is benefitting, however, when the proposed tourism project has been developed, the main beneficiaries would be the local community. The councillor perceives coastal tourism in this destination as a tool that could sustain livelihoods and eradicate poverty on condition that the proposed resort is fast-tracked, with facilities such as the playgrounds, ablution facilities, restaurants, hotels and the development of a commercial hub with a variety of shops. Capacitating the local community with training and skills required in the tourism industry could also assist in the eradication of poverty that is rife in the study area.

According to the councillor, the local community makes decisions about the development and management of Nonoti Beach through Inqaba Trust which does not take and/ or make decisions all by itself, but in consultation with KwaDukuza Local Municipality and the conservation agencies such as WESSA, KZN Ezemvelo Wildlife and others. The findings of this study reveal that improvement is needed in involving the local community in coastal tourism planning and management. This improvement includes fast-tracking skills development, capacity building and training of the local community to position them to play an active role when the proposed tourism project is developed, and is up and running. The other improvement would be awareness creation on the important role played by tourism and the influx of tourists in this tourist destination.

Available literature (Ndlovu et al 2017, DEA 2014, NTSS 2012) asserts that tourism development in any tourism destination has the potential to create jobs and stimulate entrepreneurship through the development of Small, Medium and Micro enterprises (SMMEs). Coastal tourism at Nonoti Beach, the development of the proposed Nonoti Beach Resort in particular is expected to create job opportunities for the local people. The local community expects this development to sustain their lives through the development of tourism related SMMEs. In the feasibility study of the proposed beach resort, there is a plan to develop the cultural village, where the political activists such as Nelson Mandela, Albert Luthuli and others used to meet during the apartheid era (Hatchuel 2014, Sivest 2011), and which is to be solely owned and managed by the local community. The local community perceives this project to improve their lives and what influences this perception is the state of poverty in the area, as well as the information given to them by various stakeholders involved in the project during consultative meetings. 
Russel (2011) proposes that tourism related sporting events inspire millions of people every year and they are important for economic development as well as promoting the image of a destination. This notion is confirmed by the ward councillor when he states that

As the democratically elected leadership, we perceive sports as the activity that has the potential to unite people from different lifestyles, therefore, it is in the plan of KwaDukuza Local Municipality to ensure the construction of a classy stadium at Nonoti Beach that will host various sporting activities which we believe could encourage domestic tourism and create unity between tourists and the local community. The building of a conference centre and the hosting of various events at Nonoti Beach is in the IDP of the local municipality and is anticipated to enhance the image of this destination and to improve the economy of the local people, thereby eradicating poverty, which is rife in the area.

The sea at Nonoti Beach could be perceived as a natural resource that could be used to improve the lives of the local community, but this is not happening due to the challenges that this community experiences, which further limits their participation and involvement in the management of tourism in this coastal destination. The councillor highlighted the following challenges experienced when involving the local community in the coastal tourism issues at Nonoti Beach.

The greatest challenge limiting the local community participation and active involvement in coastal tourism at Nonoti Beach is the fact that land zoning is meant for two projects, that is, the housing project and the commercial development. The community is now getting impatient due to the slow pace of delivering on the housing project. The local community wants houses. Even the commercial development is delayed because there are different service providers mandated to deliver on the projects earmarked for this area. The other challenge is that there is no clean, piped water in the area. The greatest challenge is that implementation of the resort development project adopts a piecemeal approach due to separate mandates, with the EIA funded by TKZN, TIKZN, IDC and the housing project facilitated and coordinated the Department of Human Settlements and the local municipality.

The narrative of the Respondent above proves that the different stakeholders with a mandate to develop and promote tourism in the study area work in isolation from the other and holistic planning is recommended in order to overcome the identified challenges. The councillor suggested open communication and improved consultation regarding the project to improve relationships with the community.

Regarding the skills available amongst the local community, the councillor revealed that it is not easy to say which skills exactly are available, as no skills audit has been conducted in the past five years. The findings of this study reveal that the greatest challenge limiting the participation of the local community in coastal tourism at Nonoti Beach, is the lack of relevant skills, skills such as financial skills, management skills, entrepreneurship skills, tour operating skills, as well as skills on customer service excellence. The other limiting factor is competition and power struggles between various powerhouses, such as the municipality, traditional leadership and Inqaba
Trust. The councillor agreed that Inqaba Trust is responsible for making decisions about the development of the proposed Nonoti Beach Resort and stakeholders such as TKZN, TIKZN and IDC make suggestions and recommendations.

The findings of this study reveal that the local community's expectations with regards to coastal tourism at Nonoti Beach is tangible benefits in the form of jobs, houses, the development of basic infrastructure such as roads, electricity and water supply. The community also expects stakes through profit sharing. These expectations emanate from the information shared with them regarding the anticipated resort development project, as well as the clear and open lines of communication between the community and the stakeholders mandated to facilitate and coordinate the development of the proposed resort.

\section{Inqaba Trust as a representative of the local community}

Inqaba Trust is an organisation that manages the land that the community received through the land claims process, on behalf of the community. Respondent 2 has the following to say about the background of Inqaba Trust and the significant role it plays to ensure the wellbeing of the local community:

Inqaba Trust is an organization that is responsible for the welfare of the residents of Nonoti Beach, which was formed after 300 households received settlement from the land claims process. When the democratic government made a call for the previously displaced people to come forward and claim back the land lost during the apartheid era, the Nonoti Community then formed this organization. Mr. Michael Mbokazi who has since passed away and other old-aged women, some of whom are still alive and others have passed on, led it. The trust was mandated to formulate a strategy on how the settlement could be used to sustain livelihoods and improve lives of the local community.

Lahiff, Davis and Manenzhe (2011) highlight the importance of joint ventures and close working relations amongst stakeholders. The findings of this study reveal that Inqaba Trust does not work in isolation and independently from the other stakeholders but affirm that Inqaba Trust is working closely with other governmental departments such as IDC, TKZN, eThekwini Municipality, TIKZN and others. Several meetings have been held with these government agencies, to come up with a plan to develop the proposed Nonoti Beach Resort. Respondent 2 revealed that Inqaba Trust facilitated the claiming of the land back to the displaced community of Nonoti Beach through Land Reform and Redistribution process. The claim was approved and the settlement made in favour of the community, which was then given a document, which explains how Inqaba Trust operates. Inqaba Trust is responsible for the welfare of the community, the land, and the way it should be utilized; therefore, this organisation is responsible for the development of the entire community of Nonoti Beach.

\section{E. PERCEPTIONS OF TOURISM ENTERPRISES OPERATING AROUND NONOTI BEACH OF THE LOCAL COMMUNITY}

$\mathrm{N}=5$

Hotel and Conference Centre $=2(40 \%)$

Guest Houses $=2(40 \%)$

Private self-catering $=1(20 \%)$ 
The businesses that participated in this study were selected from two neighbouring small towns, namely, KwaDukuza and Zinkwazi Beach. When this study was conducted, Nonoti Beach did not have any formal tourism facilities and businesses since the proposed beach resort is yet to be developed, which is the main reason that prompted the researcher to use tourism business in the nearby towns. 40 percent of the tourism businesses that formed a sample of this study were hotel and conference centres that cater for weddings and conferences that have holiday-makers as well as contract workers as their clientele. 40 percent were guesthouses that can be classified in the category of accommodation establishments, which cater for the visitors accommodated in these establishments. 20 percent of the participating businesses offer accommodation but are self-catering, whereby visitors bring their own food and are provided with the stove and utensils to prepare it. 80 percent of the participants in participating tourism enterprises were individuals in the capacity of a Manager and 20 percent was a husband and wife operating in the capacity of a management couple.

4.5.1 The level of communication between tourism businesses and the local community in the study area

80 percent of the participating businesses indicated that there is a high level of communication between themselves and the local community. 60 percent indicated that they employ them on both the permanent and part-time basis depending on the demand due to the establishment having an increased number of visitors, which is often times experienced during the festive season and the school holidays. 100 percent of the participating businesses indicated that the members of the local community do not use their establishments as visitors, but the people who use their services are mostly outsiders. 80 percent of the participants indicated that they have a good working relationship with the local community, with no notable incidents of theft, robberies, or break inns. The good working relations between the tourism businesses and the members of the local community was confirmed by Respondent 10 , a manager in one of the tourism enterprises who said

We work amicably with the local community, we even share goats, our goats mingle with theirs, we know exactly which goats are ours and they too know theirs. The owner has owned this establishment for 13 years now and he never had any conflicts with the local community. There are also other farmers on either side of this establishment, black farmers, Indian farmers, white farmers but we have never experienced any conflict with any of them. I think being located far from town and being rural assists in our operations and peacekeeping. Tranquillity of the area the establishment is located in, works to our own advantage

4.5.2 The extent to which tourism businesses support local community initiatives

60 percent of the participating tourism businesses indicated that in addition to the permanent staff they have under their employ, many other local people are employed on a temporary basis to help as gardeners, waiters, also as barmen, more especially during the peak season. Respondent 13 confirmed this when he said
On top of the ten permanent staff members, but whenever there are functions, the establishment makes a call for fifteen to twenty people all from the local community.

40 percent of the participating businesses revealed that they equip the members of the local community with skills by training them in the hotel industry, in hospitality, to give them an opportunity to improve the economy of the community and with the understanding that the knowledge given to them could be used to open tourism related jobs in their own areas. As much as these jobs provided to the local community look like seasonal and/ or casual, jobs that come and go, but the participants indicated that they have functions often, which makes the local community to have jobs most of the time.

4.5.3 Recommendations to enhance local community's involvement and participation in coastal tourism in the study area

The findings of this study reveal that there is a lot of development taking place in the North Coast. One of the recommendations was to get other businesses to learn more about the hospitality industry because of the development in the area, resulting in increased number of people getting accommodated in the accommodation establishments in the area. 20 percent of the participants indicated that they get so much business from the people who are directly involved with the business development in the area. He indicated that North Coast is very popular, and a lot of development in the area is from the tourism sector. 40 percent of the participating businesses revealed that the local community should make themselves available to learn more about the industry, 60 percent indicated that the members of the local community should upskill themselves in the tourism trade to encourage them as businesses to involve them. 20 percent stated that the members of the local community approach them for jobs and, most of the time, they respond by giving them jobs whenever they are available. The major challenge raised by the same manager is that the majority of the local people are illiterate and are unable to communicate through the medium of English, which makes it difficult to consider them, but indicated that those who have some understanding of English, no matter how little, are given jobs, upskilled and trained. In order to reap maximum benefits, all they need to do is only to avail themselves to take up on the available opportunities. 100 percent of the participating businesses indicated that there are no big projects to which they have involved the local community. 20 percent indicated that they hired the community members in the construction of the road leading to the establishment, not only for them, but also for use by the local community and other businesses within the area.

The majority of the businesses (80\%) who participated in this study indicated that they do not have problems with hiring the local people in their establishments, but acknowledged the lack of tourism related knowledge and skills amongst them as well as good working relations with them. Respondent 10 confirms this when he said

The local community is friendly and they are always eager to learn which encourages us to prioritise their employment, training and up-skilling. It should be noted that not everybody learns at the same time, others learn faster than others and as 
an establishment, all we need is to be patient with them. One of the casual workers here is 23 years of age and is doing matric. If he is not at school, he is a cane cutter in one of the farms and he comes here for waitering and in the near future he will be working at the bar and what is more encouraging is that he is very willing to learn. Their willingness to learn and again I am going to emphasise more on the good relationship we have with them. Most of them wait to take a lift from us if they go to KwaDukuza because they will have to walk all this way to the main road before catching a taxi, so they wait for us to get a lift. They are all very very nice.

The participating businesses are hopeful that the members of the local community will one day be knowledgeable about and skilled in the tourism sector, but only with time. Respondent 12 indicated that as tourism businesses they need to be patient with them and give them a chance, considering the fact that tourism is a new industry for them. This is what he had to say about the local community in relation to coastal tourism in the locality.

I think eventually, yaa, if we train them as we are and they learn at the required speed but at this level no, they do not have the required skills. One or two of them who are permanent workers here, specifically this lady who has worked here for a longer time, has outstanding management skills and is on top of her game. She has been an employee here for seven years now, she is capacitated and empowered to a point where she makes her own decisions, and uses own discretion without having to wait for management. Tourism is still new to the local people, therefore a strange industry altogether, so they lack exposure but with time, they will learn more and they might be encouraged to participate when they have a better understanding and have been exposed more. It should also be noted that tourism industry requires long hours, hard work and it is not for sissies. Every day in the tourism industry is a Monday, no weekends but they are getting involved considering the fact that it is still developing and is coming with so many opportunities for career development. For one to succeed in the tourism industry, one needs to have it in him, to be passionate about the industry, and to love people, even if you are not hospitable, but you should learn to be hospitable, one also needs to be diplomatic because the golden rule is that the customer is always right. What hinders the local community active participation in coastal tourism is lack of exposure and limited understanding of how the tourism sector works since the industry is still new to them. It also needs to be noted that for a long time, the local community has been working in the sugar cane plantations, cutting cane and were not involved in tourism.

The notion above is confirmed in NTSS (2011) and NTSS (2012), where it is stated that tourism is perceived as a lost opportunity for South Africa due to her apartheid history, whose legacy is more noticeable to the black communities. For a long time, tourism was regarded as a White man's thing and that impacted negatively on the local community's perceptions of this economic sector. Respondent 12 further elaborates on the challenges of tourism as a sector to the local community:

The industry is also very challenging for the elderly but the young ones are in a better position to understand how the sector works. The other challenge is that there are no jobs, even if people have gone to universities and are graduates but some of them still struggle to get a job. They need to focus on finishing school, get at least a matric and study further and get a diploma in tourism, hospitality, management, again the willingness and eager to work long hours. There are many skills required in the tourism and hospitality industry, in the kitchen, they can be chefs and the maintenance of the yard, the ground, handymen, cleaners, looking after the stock in the farm establishment, there are a lot of skills in the industry, not everybody can be in management, but others can be in construction, plumbing, etc.

4.5.4 Improvement needed on the local community for active involvement in coastal tourism

The participating businesses indicated that the local community needs to find out more about the industry, be open to training for various skills including plumbers, electricians and caring for the livestock. There are many fields in the industry and not everybody is meant for management, other people may be good in vocational careers like plumbing and the tourism industry is all of it. They also need to open their minds and eyes and look for opportunities they can take in order to improve themselves. They also need to explore the available opportunities because opportunities cannot come to you but they need to go out and look for them. The participants also highlighted the fact that there is a chance to grow in the tourism industry. Respondent 11 confirms this when he said

The local community expects to get jobs. Some of them who are already working want to grow in the industry, like someone who is a runner responsible for clearing tables, then move up to be a waiter and works hard with the hope of ascending to a Bar man, etc. We as management do take note of those who work an extra mile and we make sure that in the next function they work in a better level than before.

The sentiments of Respondent 11 above are supported by Leijzer and Denman (2013) who advocate for "a bottom-up approach to development whereby local communities set their own goals and make decisions about their resources without having derived their ideas from local, regional, central or international government agencies". What is suggested here is that the members of the local community should learn to take initiative in projects that will help them and also be prepared to work hard when the opportunity has availed itself.

\section{CONCLUSION}

The findings of this study reveal that the local community of Nonoti Beach does not participate in the management of tourism that is taking place in their ancestral land. They have different opinions concerning stakeholders with a custodial role of managing tourism in the area. Others think it is the local municipality, others think it is Inqaba Trust and others are clearly unsure. The local community is positive about the development of the proposed beach resort and the housing project that are planned for the study area. The challenge lies with the delay in both these projects, which is due to the fact that these projects are to be implemented by two different stakeholders, that is Department of Human Settlements and the investor in the form of IDC. The nature in which these two stakeholders operate is fragmented to the detriment of the local community. Although the sea and the marine resources have the 
potential to uplift the local community, the findings of this study reveal that the majority of the community uses the sea for recreational and spiritual purposes and only a minority uses it for economic gain. However, they are hopeful that once the proposed beach resort is operational, they will get jobs as well as entrepreneurial opportunities. They are also expecting to benefit through profit sharing and the development of basic infrastructure. The majority indicated that they do not get jobs from the tourism enterprises in the locality, and those who do, only get menial, low paying jobs, which do not contribute much to sustaining their lives. The local tourism businesses acknowledge the lack of skills amongst the members of the local community, but are prepared to train and upskill them as long as they avail themselves and are prepared to work hard.

\section{ACKNOWLEDGMENT}

The author acknowledges the research support provided by the Department of Higher Education and Training (DHET) University Capacity Development Programme (UCDP). I would like to thank the government agencies, the tourism businesses and the Nonoti community for providing insights and expertise that assisted in the compilation of this paper.

\section{REFERENCES}

[1] M. Aliber and B. Cousins, "Livelihoods after land reform in South Africa". Journal of Agrarian Change Vol. 13 (1) pp140- 165, 2013. https://doi.org/10.1111/joac.12012

[2] T. Binns and E. Nel, "Tourism as a local development strategy in South Africa". The Geographical Journal, 168 (3) pp235-247, 2009. https://doi.org/10.1111/1475-4959.00051

[3] U. Bob and S. Bronkhorst, "Environmental conflicts: Key issues and management implications". Journal on climate change 10, no2 PP 9-30, 2010 .

[4] S. Burton, Proposed Nonoti Beach Tourism Development: iLembe District Municipality, KZN. Faunal Assessment Report. South Africa. Industrial Development Corporation (IDC), 2012.

[5] N. Cavlek, A. Ladkin and C. Willis, "All at sea: "Sustaining livelihoods through maritime tourism in Croatia". African Journal for Physical Activity and Health Sciences, pp 66-88, June 2017.

[6] N. Cele, J. Ndlovu and T. Phoofolo (2017). "Stakeholders perceptions about recreational events within Marine Protected Areas (MPAs) in the South Coast of KwaZulu-Natal, South Africa". African Journal for Physical Activity and Health Sciences, pp115-132, June 2017.

[7] Department of Environmental Affairs South Africa's national coastal management programme. Cape Town: Department of Environmental Affairs, 2014.

[8] Department of Environmental Affairs Oceans and Coasts: South Africa. Cape Town: Department of Environmental Affairs, 2017.

[9] Department of Environmental Affairs and Tourism National Tourism Sector Strategy. South Africa: Pretoria, 2011.

[10] Department of Tourism. National Tourism Sector Strategy. South Africa. Pretoria, 2012.

[11] T.E. Fish and A.H. Walton, (2012). Sustainable tourism capacity building for marine protected area. Parks vol 18(2). https://doi.org/10.2305/IUCN.CH.2012.PARKS-18-2.TEF.en

[12] J. Glazewski, Ocean governance: A first step. South African Journal of Science, 109 (3/4), 2013. https://doi.org/10.1590/sajs.2013/a011

[13] Global Ocean Commission, Modernising Ocean Governance. Policy Options Paper\#10. Oxford, United Kingdom, 2013.

[14] B.J. Goble, T.R Hill, and M.R. Phillips, "An assessment of Integrated Coastal Management Governance and Implementation using the DPSIR Framework: KwaZulu-Natal, South Africa". Coastal Management, 45 (2), 2017.

https://doi.org/10.1080/08920753.2017.1278144
[15] Z.S. Gumede Tourism participation in the Isimangaliso Wetland Park: Perceptions, practices and prospects. Unpublished MA thesis. KwaDlangezwa: University of Zululand, 2009.

[16] W. Harrison, Stakeholder theory, state of the art. Cambridge: Cambridge University Press, 2013.

[17] M. Hatchuel, Life is not always a beach. http://www.thistourismweek.co.za/newsletter/life-isn't-alw ays-a-beach/ 2014. Accessed 17/03/2015: 15h00.

[18] C. Hillenbrand, K. Money and A. Ghobadian Unpacking the mechanisms by which corporate responsibility impacts stakeholder relations. British Journal of Management, vol 24, pp 127-146, 2013. https://doi.org/10.1111/j.1467-8551.2011.00794.x

[19] P. Hottola, Tourism Development Strategies: Lessons from the Southern African Experiences, in Tourism Strategies and Local Responses in Southern Africa, edited by Petri Hottola, Walingford: Cabi, pp183-202, 2009.

[20] M.R Jury. "Development strategies for a coastal resort in Southern Mozambique." African Journal of Business Management volume 5 (2) PP481-504, 2011.

[21] M. Leijzer and R. Denman, Tourism development in coastal areas in Africa: promoting sustainability through governance and management mechanisms. Madrid: UNWTO, 2013. https://doi.org/10.1016/j.tourman.2010.09.002

[22] J.E. Mbaiwa, Changes on traditional livelihood activities and lifestyles caused tourism development in Okavango Delta, Botswana. Tourism Management 32(5) pp1050-1060, 2011.

[23] L. Meskell, The nature of heritage: The new South Africa. Pretoria: Schaik Publishers, 2011.

[24] J. Ndlovu, Community tourism projects as a vehicle for creating entrepreneurial opportunities in KwaZulu-Natal, South Africa. African Journal for Physical Activity and Health Sciences, pp14-31, 2017.

[25] K. Omeje and C.M.A. Kwaja,. Exploring the conflicts between traditionalism and modernity. Kenya: CODESRIA, 2017.

[26] Operation Phakisa, Unlocking the economic potential of South Africa's oceans. MPSG Final Lab Report, (2014).

[27] A. Russel, The development and management of beach resorts: Boracay Islands. Singapore: Cornell-Nanyang Institute of Hospitality, 2011.

[28] S.A. Sivest, Proposed Nonoti Beach Tourism Development in the KwaDukuza Local Municipality, KwaZulu-Natal: Draft Environmental Assessment Report. South Africa: Durban, 2011.

[29] M. Sowman, and R. Wynberg (ed), Governance, equity and sustainability in Sub-Saharan Africa: An introduction to the discourse. Routledge: Earthscan, 2014.

[30] M. Sowman and R. Wynberg (ed), Governance for justice and environmental sustainability: Lessons across natural resource sectors in Sub-Saharan Africa. Routledge: Eartscan, 2014.

[31] V.M.Waligo, J. Clarke and R. Hawkins, Implementing sustainable tourism: A multi-stakeholder involvement management framework. Tourism Management (66), pp342-353, 2013. https://doi.org/10.1016/j.tourman.2012.10.008

[32] T. Walker, Ocean Governance: South Africa Getting its House in Order. ISS Africa, 2013.

[33] W. Wiccomb and H. Smith, Customary communities as "peoples" and their customary tenure as "culture": What we can do with the Endorors decision. African Journal of Human Rights Law, vol 11. Pp422-436, 2011 